\title{
Use Object Oriented, Visual Modeling, PDA to Construct Specification Inquir- ing, Quality Inspection and Site Recording System
}

\author{
Yan-Chyuan Shiau, Miao-Ling Huang and Tsung-Pin Tsai \\ Chung-Hua University, Department of Construction Engineering \\ 707, Sec. 2, Wu-Fu Rd., Hsin-Chu, Taiwan, 300, R.O.C. \\ ycshiau@ms22.hinet.net
}

\section{ABSTRACT}

The construction market has been declined significantly for last few years in Taiwan. In order to survive in such difficulty environment, we have put some efforts on improving construction methods, creating new materials, and some other aspects. However, the most important factor to assure the success for construction companies is to perform construction management practically. We need to control each stage, from bidding, purchasing, and construction, very carefully so we can stay in good competition and maintain good profit.

In this research, we use Object Oriented, Visual Modeling, Rational Rose, and UML, combined with Delphi to construct the Construction Management Integrated System (CMIS). To link with PDA, user can inquire contract, specification, quality inspection tables and other related information.

This system can provide bi-directional data transformation, which allows user to down load data from PC to PDA and collect site information from PDA to CMIS in PC. The advantages of this system are as following: (1). to systematically make up the specifications and quality inspection tables, (2). to transform specifications, requirements, and other necessary information to PDA so engineers can read them immediately, and (3). to collect site information and integrated to main system. This can be used to perform cost control and decision-making.

\section{Keywords : Object Oriented, Visual Modeling, Construction Management, PDA, Quality Inspection}

\section{REASON AND PURPOSE}

During the process of automation in the construction industry, people often find themselves facing many difficulties. This was mainly because they tried to do a good job on automation of construction management; and spent lots of money and time to buy the socalled "Integrated Construction Management System", or look for a software company on development, yet the expected result was hard to achieve.

In this research we use the Object Oriented and Visual Modeling combined with the user with Object Oriented Analysis (OOA), Object Oriented Design (OOD) and Object Oriented Programming (OOP) to develop by the system; which can solve the defects of traditional software development such as incompatibility of software to users' needs, the system can hardly cope with change of needs, and the difficulty of software maintenance and expendability.

Due to the advancement in computer hardware and software, we now have the palm computer - PDA with little volume and light weight. No more forms and sheets need to be filled in manually, since the site personnel may record data via PDA and transfer information needed for the site from previous entering action; so actual work situation can be checked immediately and reduces the time of travel and mistakes on documents.

The data collecting system includes various auto- matic and integrated electronic forms for receiving information entered into the palm computer - PDA. There are the following advantages on using a PDA: (1) after integration, only basic non-repeated data are needed; because (2) when PDA enters data such as "Specification Inquiring, Quality Control and Administration of Construction Records", the integration of data will be higher. Thus the quality of data integration and promptness will be enhanced remarkably.

From the above features, the service quality on internet business is now better than the traditional service industry, the turnover is no longer limited by the number of staff, and the productivity is even larger than what the service industry can compete with. Should the construction industry intend to improve its productivity and competitiveness, it shall not exclude this trend of industrial evolution.

In respect to the above-mentioned current situation, we have developed a system of "Specification Inquiring, Quality Inspection and Site Recording System", which may perform a vertical integration thoroughly on the management of the construction site; as well as integrating all relevant data within the project lifetime via the Internet, and save the calculation result of preliminary work in the system for later operation. In this way, a large amount of repetitive calculation and key-in work can be saved, as well as prevention human error during calculation process. By analyzing according to actual project requirement, this research 
has completed four modules in the system, namely the Basic Database, Item Specification, Daily Site Report and Quality Control.

\section{FUNCTIONAL REQUIREMENT}

The structure of "Specification Inquiring, Quality Inspection and Site Recording System" was based on the mechanism of "Using Object Oriented and Visual Simulation to build Construction Management Information System I \& II" (overall structure is shown on Fig. 1), and the main modules include:

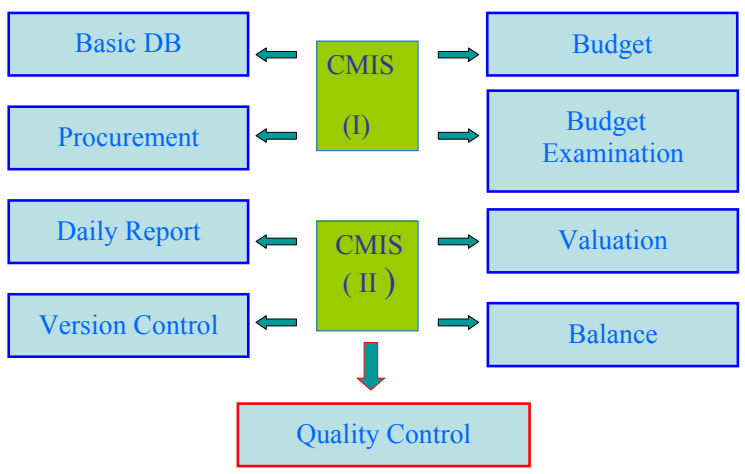

Fig.1 Structure between CMIS and this research

A. Build structure of basic information for the system, the database of work items are classified as large items, medium items, detail items, projects, buildings, floors, rooms, schedules and breakdowns etc.

B. Develop the Specification Module of that allows user to search for regulation on various work items, which act as important basis of site management.

C. Develop the Daily Site Report Modile that allows user to record number of people, machine, materials and work done on various items, which act as important reference for assessment and valuation.

D. Develop the Quality Inspection Module that allows user to enter data of quality inspection and print out its result, so effective quality management is achieved.

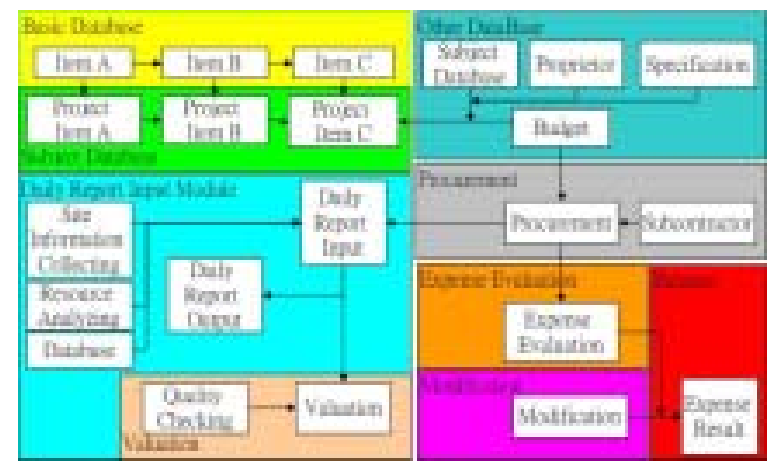

Fig.2 Relation between CMIS and this research

\section{FLOW CHART OF RESEARCH}

The flow chart of research for this program is shown in figure 3 .

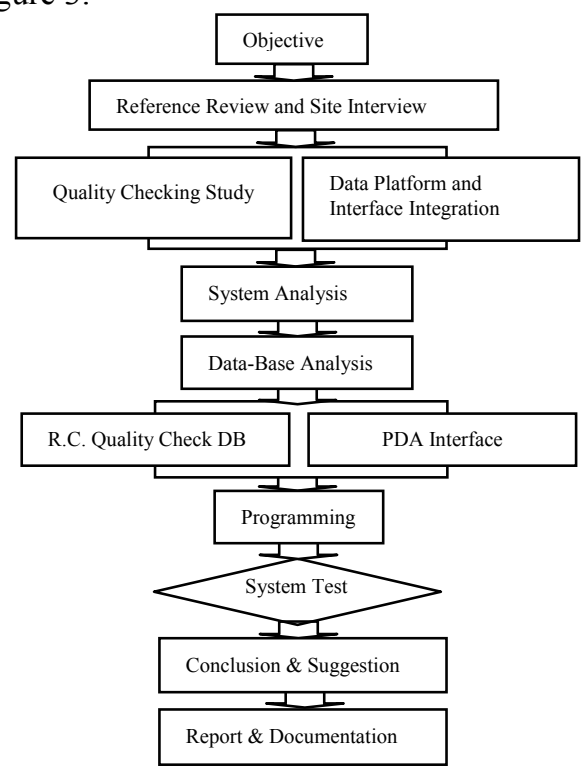

Fig.3 The flow-chart of this research

\section{DISCUSSION ON DATABASE STRUCTURE}

\subsection{Analysis on database structure}

The structure of the database is the main core of the system, once an error occurs in the frame, or users' requests are mismatched, the whole data flow will be in error, and put out unexpected information. Therefore, construction of a database frame that complies with functional requirements of the system is the key of success on a project.

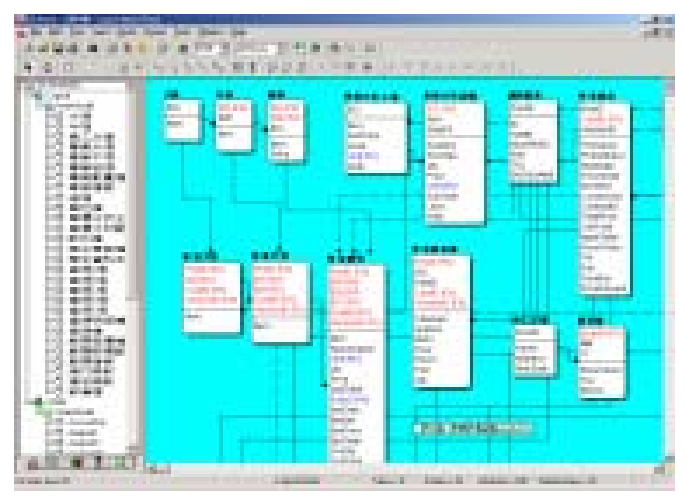

Fig.4 Relational model of the database

With the advancement of information technology, the development of database system has been performed from the traditional "Relational Database" to the "Object-Oriented Database" (OODB); and the OODB has become a major trend of managing system for database. This research uses the "ER /Studio (Entity-Relationship)" to produce an "ER Diagram", and then based on this model to plot the data flow chart in accordance with the user's requirement, so that an E-R Model is built. After defining the fields and relationship between fields on each data table, the actual database is then constructed, and becomes 
the actual relationship database (as shown in figure 4).

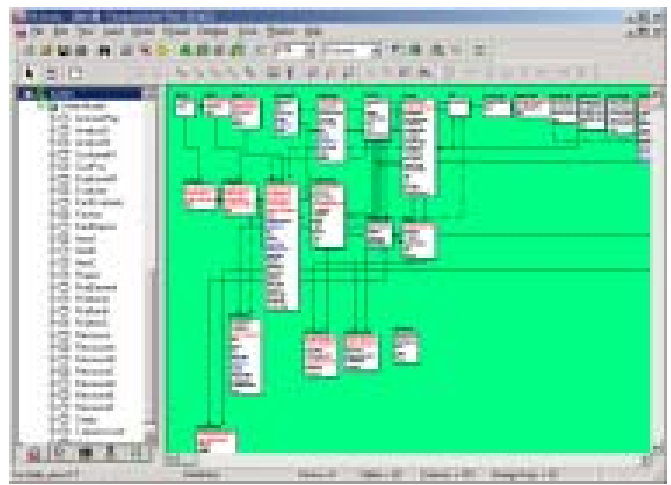

Fig.5 Physical model of the database

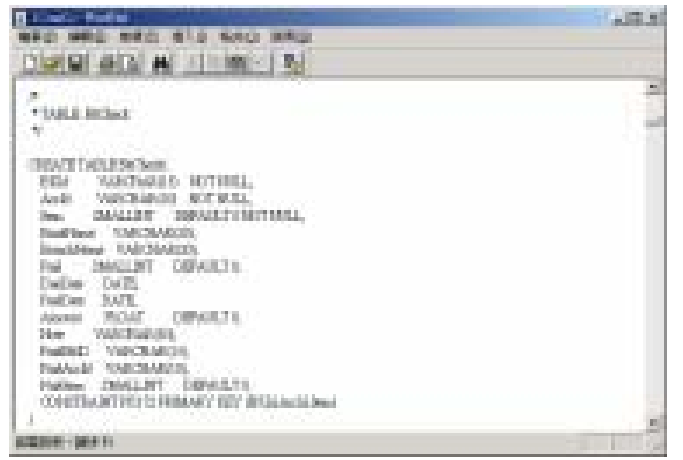

Fig.6 Script file of the database

After completion of ER/Model, we can use tools provided by the software to transform the database frame into a Script File (as show in figure 6) for database management system; which allows the Database Console to read database of the system, fields and properties of each data table, as well as connection of Primary Key and Foreign Key for each dat a table, so that the system database can be established. There are many transferable types of database, which are compatible with most of the major database management systems (as shown in figure 8).

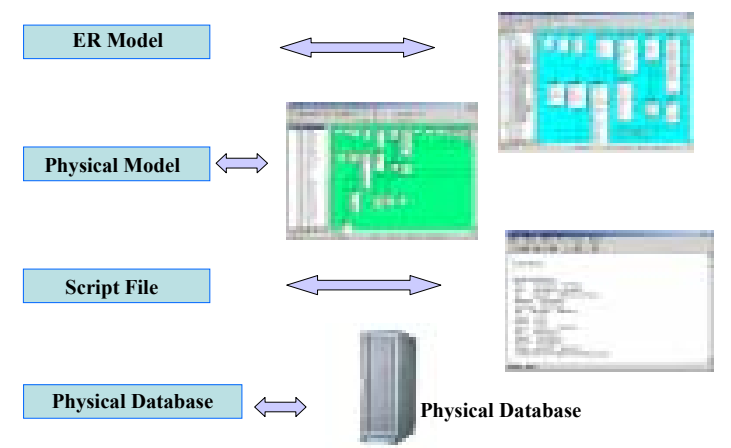

Fig.7 Flow chart using ER/Studio to generate Database

\subsection{Specification Module}

The construction Specification is the basis between the site contractor and sub-contractor on communi- cation of what to do with certain work items. Therefore, if there is a regulation for reference at all times during site construction, it will provide great help.

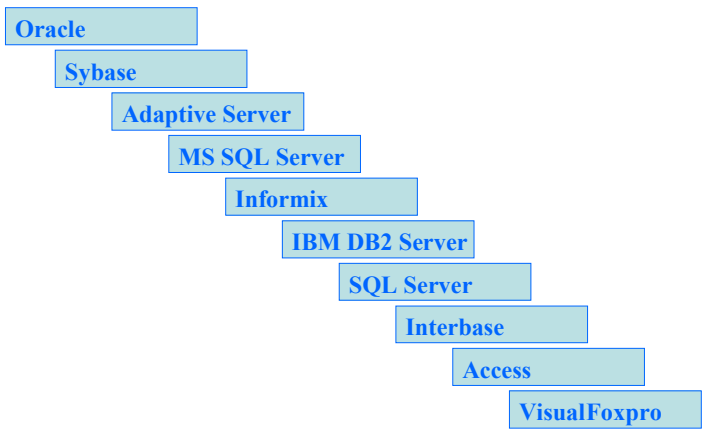

Fig. 8 DBMS that is compatible with ER/Studio

Based on the construction stages, the construction Specification is divided into the following categories:
A. Temporary work
B. Underground excavation
C. Structural work
D. Mortar work
E. Interior finish
F. Exterior finish
G. Doors and windows
H. Kitchen and toilet equipments
I. Electrical and mechanical work
J. Cleaning
K. Landscaping
L. Miscellaneous
M. Material

Figure 9 shows the screen of the searching system for formwork specification.

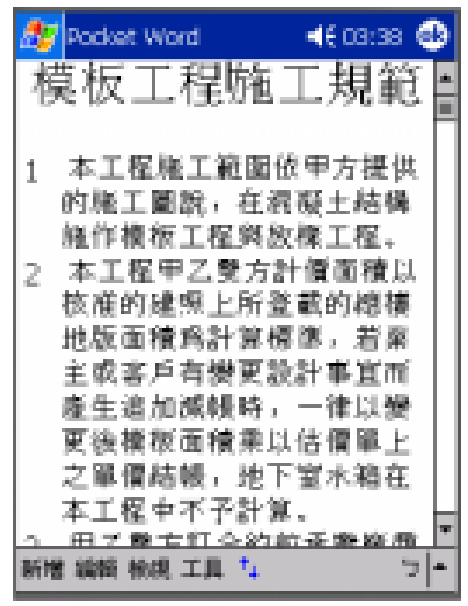

Fig.9 Specification Inquiring Dialog

\subsection{Quality Inspection Module}

During project execution, there are a tremendous amount of problems for the site manager to deal with from the start of work till completion of the project; this includes control of construction progress, arrangement of construction machines, cooperation of sub-contractors, arrangement of workers, entry of 
material, arrangement of stored material, management of work quality, maintenance of site safety, handling of design change and mediation on dispute etc., where the range of professional information is extensively wide and complicated. Since the development of construction scale tends to be large and multi dimensional, the mission of how to systemize this type of problems further and how to manage the work well via computer/software systems will be the priority for site management of construction.

In the past, our construction management stayed at traditional hand recording or sending/receiving information with e-mail, and then establish relevant database by compiling manpower. This type of operation fashion would cause lack of integration between each unit and repetitive establishment of information. Furthermore, due to possible human error, possibilities of incorrect information, increasing cost, low efficiency, effect of work quality and future dispute would be created.

The current quality management in our construction industry is divided in three levels, which includes the owner and government authority, construction companies and professional contractors. For the inspection of quality control, most common procedures are filling in the inspection sheets of quality control and taking the sheets back to office for input of inspection result, where the construction personnel need to spend large amount of time and manpower on long and repetitive input of information. The construction industry has always been a industry with large amount of works, non-standardization and complicated breakdowns; thus the question of how to use the advanced hardware/software conditions from information technology and convenient wireless communication for site personnel on individual sites to input quality verification with PDA/Tablet PC, and use the wired/wireless communication to integrate such information with the main system immediately; where the contractor, construction companies, owner and government authority may access via internet and print out the result of quality verification, so that a computerized management of " 24 hours/zero distance" can be achieved is a mission worth of effort by all.

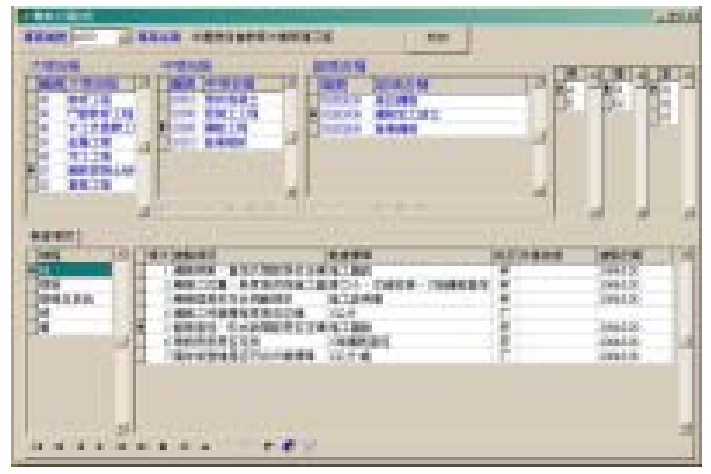

Fig.10 Steel bar erection Input Dialog

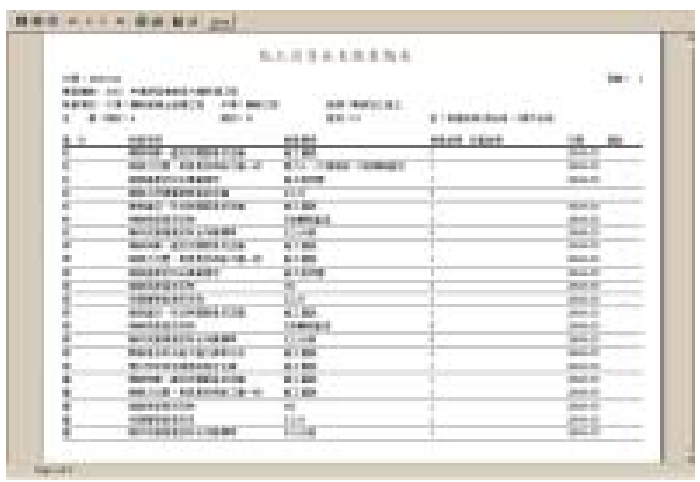

Fig. 11 Steel Bar erection Print-out

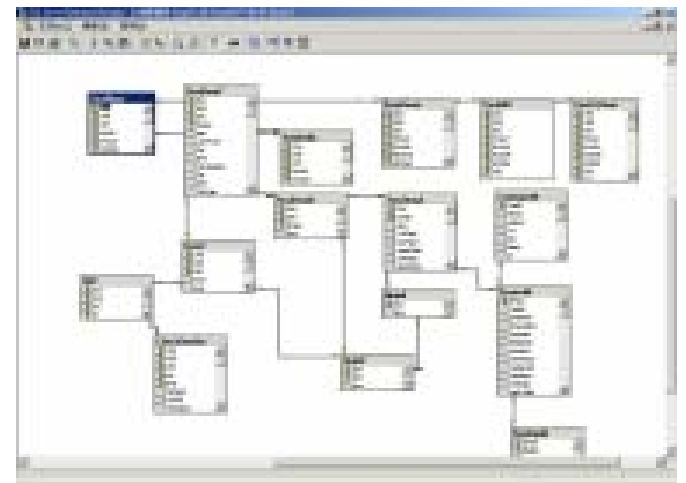

Fig. 12 PDA SQL Database Diagram

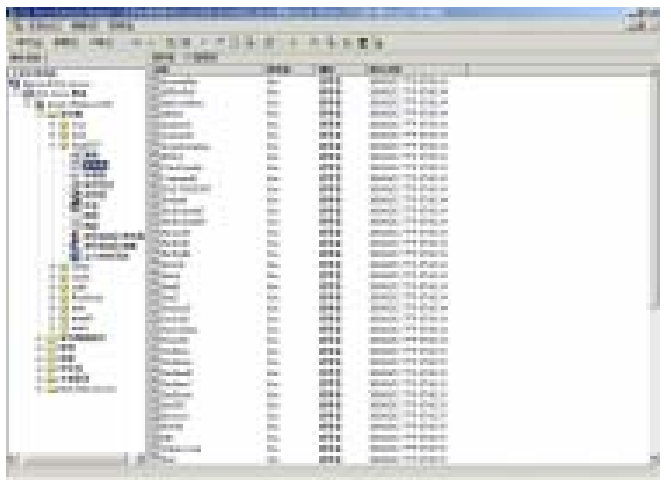

Fig.13 SQL Tables of PDA

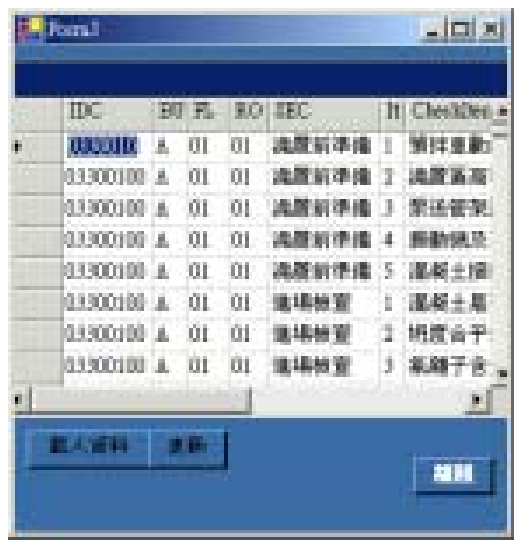

Fig.14 Quality Inspection Dialog on PDA 


\subsection{Daily Site Report Module}

The daily site work and various matter happen on site everyday, and it acts as the center of site management; where information collected from the site everyday may derive reports such as cost, progress and quality after sorting and analysis.

Since the daily work records and various matter happens on site everyday, and there are many things to be recorded, we therefore divide it into construction information, construction personnel, workers, machines, material, amount completed, work location, items of inspection, site memo and information of form completion.

The site records is not just filling in the daily sitereport, and it has to be used with other forms of records on weather, work duration, daily work hours, equipment usage, steel bar usage, amount of concrete pouring, amount of formwork and amount or earthwork; and the best is for the site records to cooperate with construction progress and network.

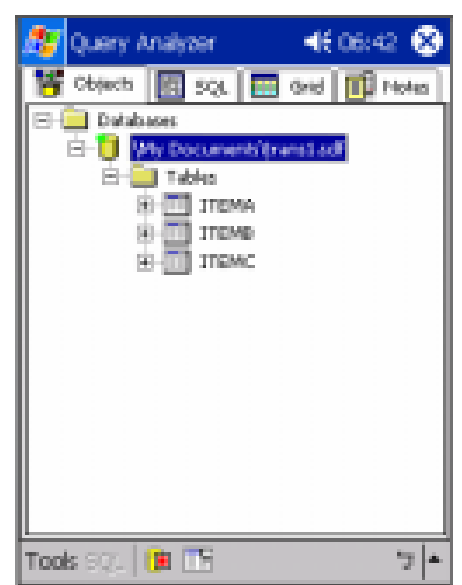

Fig.15 PDA Site Daily Report

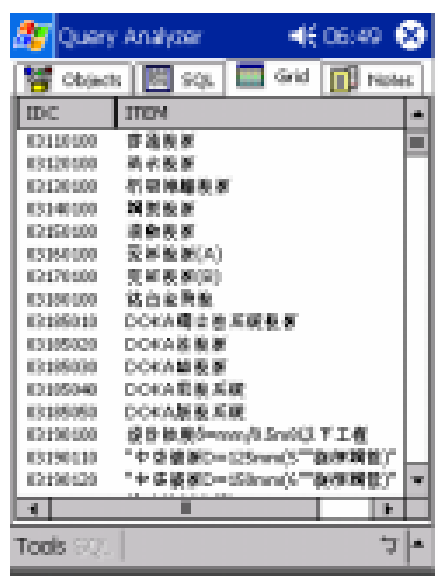

Fig.16 Use SQL Analyzer to view Site Items

This system will extract the work items for database frame of daily site report from the basic database, and then transfer them as project work items, which is followed by compiling matters that happened on site and other relevant information (e.g. material analyzing database and information of contractors etc.) recorded in the daily work report system into information needed by the project items. The frame of buildings, floors and rooms will enter the work items per work location, and output the daily site report sheets via daily compiling; as well as the output of monthly report via monthly compiling in accordance with requirements of assessing period, and provide information to the assessment information system.

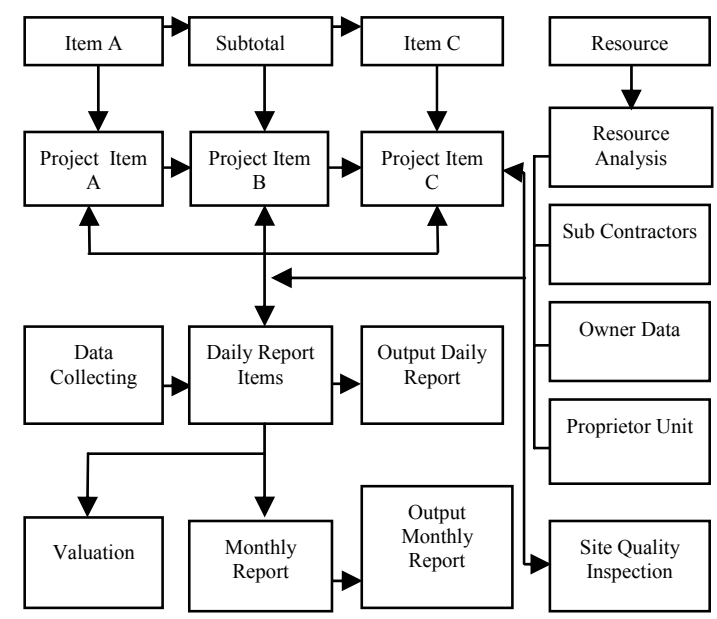

Fig.17 Daily Site Report and Quality Inspection Database

\subsection{Building, Floor and Room Hierarchy}

There is one common defect among compiling software in general building industry, namely the incapability of controlling amount of work done at every stage within limit. This research adds the frame of "Building $\rightarrow$ Floor $\rightarrow$ Room" into the basic database (as shown in figure 18), and compile with the database of project work items. If there is different rate due to different contractor on the work location included in the information of work items within the system, different part of this structure can be utilized to simulate actual execution, so the information of work items can be managed more adequately. Figure 19 shows the sample information as content of column and position of column on the information sheet for quality inspection of this system.

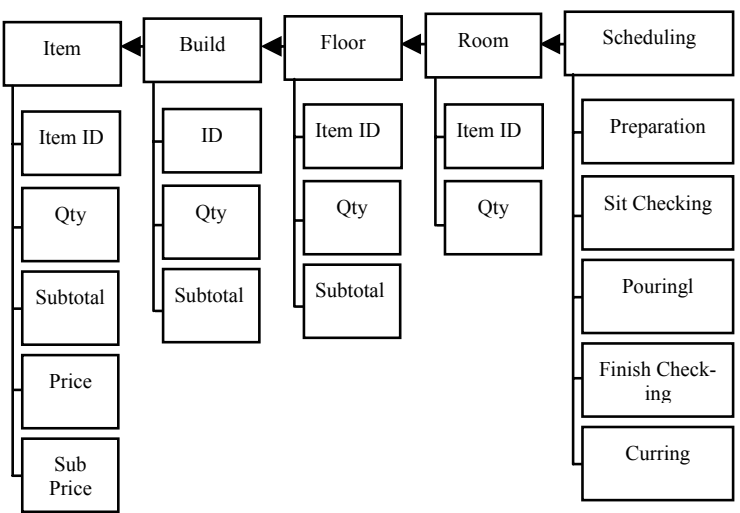

Fig.18 Build-Floor-Room Structure 


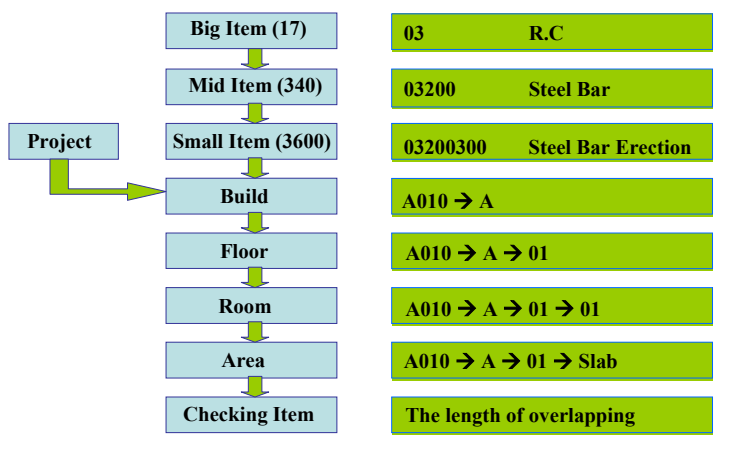

Fig.19 Quality Inspection Database Structure

\section{CONCLUSIONS AND SUGGESTIONS}

\subsection{Conclusions}

The handling via this research may contribute to the domestic construction industry as follows:

A. Collect and sort out existing systems of management in the construction market.

B. Help the overall construction industry to be familiar with the standard operation procedures and its content by using the system to unify operation procedures of construction industry.

C. From establishment of this database, unnecessary repetitive calculation on quantity and information entering can be prevented.

D. Utilize the systematic functions thoroughly, reduce traditional human errors, and carry out the managing systems and standard operations.

E. The systematic function may help decision maker to quickly find out the project content and make construction management well, so the decision maker can make better management with up-to-date information.

\subsection{Suggestion}

The consequent study of this research in the future is suggested as follows:

A. Combine with the progress managing software (e.g. MS Project, P3 etc.) for automatic compiling of work progress, and renew the information from daily work report into the progress managing software, so a up-to-date and complete construction management can be expected.

B. Compile all information on site for development of financial cost system, which can manage and control the work income and expense, as well as increasing profit for construction contractors.

C. Consideration of input the Daily Site Report into 3D animation and show work completed and construction progress.

\section{Acknowledges}

I would like to take this opportunity to show my appreciation to National Science Council, Executive Yuan, for its support of the study. Project No.: NSC 91-2622-E-216-007-CC3.

\section{REFERENCES}

[1] Abudayyeh, O. Y. and Rasdorf, W. J.,"Prototype Integrated Cost and Schedule Control System", $J$. Computing in Civ. Engrg., ASCE, 7(2), Apr. 1993, 181-198.

[2] Barr, C., "State of the Slate: Pen-based Computers," PC Magazine, Vol. 12, N0. 6, Mar. 1993, 192-193.

[3] Rasdorf, W. J. and Herbert M. J., "Automated Identification Systems - Focus on Bar Coding," J. Computing in Civ. Engrg., ASCE, 4(3), Jul. 1990, 279-296.

[4] Rowings, Jr., J.E., "Project-Controls Systems Opportunities," J. Constr. Engrg. And Mgmt., ASCE, 117(4), Dec. 1991, 691-697.

[5] Yang, H. C., "A Computerized Cost Control System for the General Contractors," Master Report, School of Building Construction, University of Florida, 1982.

[6] UML Distilled, Second Edition: A Brief Guide to the Standard Object Modeling Language (The Addison-Wesley Object Technology Series) By Martin Fowler, Kendall Scott (Contributor), Grady Booch.

[7] Software Reuse : Architecture Process and Organization for business Success By Ivar Jacobson, Martin Griss , Patrik Jonsson.

[8] Rational Unified Process - An Introduction, 2nd edition By Philippe Kruchten.

[9] Object-Oriented Software Development--A Use Case Driven Approach By Ivar Jacobson. 